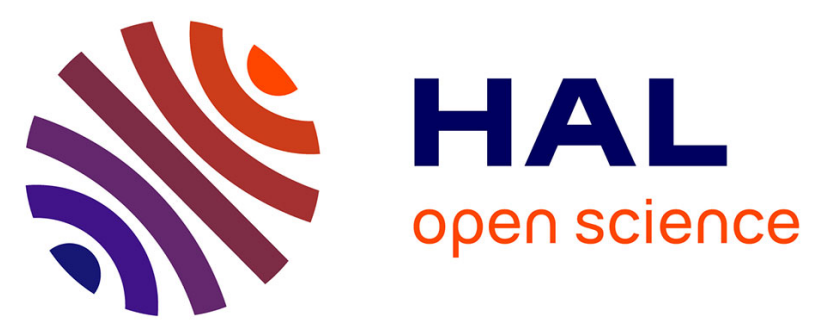

\title{
Five-year mortality in patients with diabetic foot ulcer during 2009-2010 was lower than expected
}

Coralie Amadou, Aurélie Carlier, Chloé Amouyal, Olivier Bourron, Carole-Elodie Aubert, Thibault Couture, Eric Fourniols, Georges Ha Van, Stéphanie Rouanet, Agnes Hartemann

\section{To cite this version:}

Coralie Amadou, Aurélie Carlier, Chloé Amouyal, Olivier Bourron, Carole-Elodie Aubert, et al.. Fiveyear mortality in patients with diabetic foot ulcer during 2009-2010 was lower than expected. Journal of Diabetes \& Metabolism, 2020, 46 (3), pp.230-235. 10.1016/j.diabet.2019.04.010 . hal-03009372

\section{HAL Id: hal-03009372 \\ https://hal.sorbonne-universite.fr/hal-03009372}

Submitted on 17 Nov 2020

HAL is a multi-disciplinary open access archive for the deposit and dissemination of scientific research documents, whether they are published or not. The documents may come from teaching and research institutions in France or abroad, or from public or private research centers.
L'archive ouverte pluridisciplinaire HAL, est destinée au dépôt et à la diffusion de documents scientifiques de niveau recherche, publiés ou non, émanant des établissements d'enseignement et de recherche français ou étrangers, des laboratoires publics ou privés. 
Five-year mortality in people with diabetic foot ulcer in the years 2009-2010 is lower than expected.

Coralie Amadou*1, Aurélie Carlier*1,2,3, Chloe Amouyal4, Olivier Bourron ${ }^{1,2,3}$, Carole Aubert $^{5}$, Thibault Couture 3,6 , Eric Fourniols 7 , Georges Ha Van ${ }^{1}$, Stéphanie Rouanet ${ }^{8}$, Agnes Hartemann 1,2,3

${ }^{1}$ Diabetology department, AP-HP, Pitié-Salpêtrière Hospital, 83 bld de l'hôpital, F-75013 Paris, France

coralie.amadou@gmail.com;olivier.bourron@aphp.fr;georges.havan@aphp.fr; agnes.hartemann@aphp.fr

2Inserm, CIC-1421, AP-HP, Pitié-Salpêtrière Hospital, Department of Pharmacology, 83 bld de l'hôpital F-75013 Paris, France

aurelie.carlier@aphp.fr

3Sorbonne Université, 91 bld de l'hôpital F-75013 Paris, France

${ }^{4}$ Sorbonne-Université, Inserm, Research Unit on Cardiovascular, Metabolic And Nutrition Diseases (UMRS-1166), Institute of Cardiometabolism and Nutrition, 91 bld de l'hôpital F-75013 Paris, France

chloe.amouyal@gmail.com

5Department of internal medicine, Fribourg Hospital, Switzerland

CaroleElodie.Aubert@insel.ch

6Department of vascular Surgery, AP-HP, Pitié-Salpêtrière Hospital, 83 bld de l'hôpital F-75013 Paris, France

thibault.couture@aphp.fr

${ }^{7}$ Department of orthopedic Surgery, AP-HP, Pitié-Salpêtrière Hospital, 83 bld de l'hôpital F-75013 Paris, France

eric.fourniols@aphp.fr

8StatEthic SASU73 rue Paul Vaillant Couturier,92300 Levallois-Perret,France

stephanie.rouanet@statethic.fr

* These authors contributed equally to the work

Corresponding author:

Agnès Hartemann: Diabetes department, Pitié-Salpetrière Hospital, 83 bld de l'Hôpital, 75013 Paris France

e-mail agnes.hartemann@aphp.fr

Word count: 2280 
Tables: 2; Figures: 2

Abstract

Aim

Mortality rate is decreasing in people with diabetes but if this observation also concerns patients with diabetic foot ulcer (DFU) needs additional data. This study evaluated the mortality rate at 5 years in patients with a DFU occurring in the years 2009-2010 and identified risk factors associated with mortality.

Methods

Patients who successively attended for a new foot ulcer between in 2009-2010 were followed until healing and at one year. Data on mortality were collected at year 5. Multivariate Cox proportional Hazard model was used to identify mortality risk factors.

Results

Three hundred and forty-seven patients were included: mean age was $65 \pm 12 \mathrm{y}$, diabetes duration was 16 [10;27] years; $13 \%$ were on dialysis and $7 \%$ had an organ graft. At 5 years, 49 patients (14\%) were considered lost to follow up. The total mortality rate at 5 years was 35 $\%$, and $16 \%$ in patients with neuropathy. In multivariate analysis, mortality was positively associated with age (HR 1.05 [1.03-1.07], $\mathrm{p}<0.0001$ ); duration of diabetes (HR 1.02 [1.001-1.03], $\mathrm{p}=0.03$ ); PEDIS perfusion grade 2 vs 1 (HR 2.35 [1.28-4.29], $\mathrm{p}=0$,006); PEDIS perfusion grade 3 vs 1 (HR: 3.14 [1.58-6.24], $\mathrm{p}=0.001$ ), and with the duration of ulcer during the first year (HR 2.09 [1.35-3.22], $\mathrm{p}=0.0009)$.

\section{Conclusion}

Mortality rate was not as high as expected despite a high number of co-morbidities, suggesting that progress has been made in health care of these patients. Particularly, patients with neuropathic foot ulcer had a survival rate at 5 years of $84 \%$.

\section{Key words}

Diabetes. Foot. Ulcer. Mortality.

\section{Abbreviations}

ABI Ankle brachial index

CLI Critical limb ischemia 
DFU Diabetic foot ulcer

PAOD Peripheral artery occlusive disease

PEDIS Perfusion, Extent, Depth, Infection, Sensation

\section{Introduction}

Diabetic foot ulcer (DFU) is an economic burden for many countries and induces a dramatic decrease in physical, emotional, and social functioning for patients $[1,2]$. It is associated with advanced micro and cardiovascular complications, resulting in high morbidity and a greater risk of premature death [3]. The major cause of death in DFU is ischemic heart disease $[4,5]$.

Studies regarding long term survival in patients with DFU are scare, but data coming from cohorts formed before the $2000 \mathrm{~s}$, reported mortality rates around $45 \%$ at five years [4-6]. However life expectancy has improved for the last years in people with diabetes [7,8], and therapeutic options for DFU have made progresses and are now the topic of robust international guidelines [9]. A single study in 2008 [5] suggested that survival in people with DFU before and after the 2000s could have increased, but these optimistic results were not confirmed in another study published in 2012 [10].

The main aim of our study was thus to determine the years 2010 life expectancy in patients with DFU. Identifying patients with DFU who are at high risk of premature death is important to choose the best therapeutic project with each patient. Thus secondary objective was to identify the years 2010 predictive factors for five-year mortality in patients with DFU.

\section{Methods}

\section{Population}

Between March 2009 and December 2010, all patients with diabetes and a new foot ulcer who attended a multidisciplinary diabetic foot center in a University Hospital (Paris, France), were successively included in this cohort. Patients gave oral consent for participation and agreed to be contacted (them or their family relatives) to obtain information on their outcomes. The study was in accordance with ethical legislation in France.

ClinicalTrials.gov registration no. NCT03782129

Wound healing date was recorded until 12 months after inclusion. Five years after inclusion, patients or their family relatives or their family physician were contacted by phone 
to know if they were still alive. If necessary we consulted clinical files or the registry office of the patient's birth town hall. If there was no mention of death on birth certificate, the patient was considered to be still alive. If the patient was not born in France, and the information could not be obtained, the patient was considered lost to follow-up.

\section{Foot ulcer management}

All patients with DFU were treated according to the most recent guidelines from the International Working Group on the Diabetic Foot (IWGDF), particularly for Peripheral Artery Occlusive disease (PAOD), and the French Society of Infectious Diseases. Hospitalization was required in case of wound complications.

\section{Database}

At inclusion data were collected for the following variables: age, sex, diabetes type and diabetes duration, insulin therapy, BMI, dialysis, kidney or pancreas-kidney transplant, active smoking, presence of a relative at home or not, date of ulcer occurrence, history of previous DFU or amputation. Severity of ulcer was graded according to the University of Texas Diabetic Wound Classification System [11] and to the PEDIS (Perfusion, Extent, Depth, Infection, Sensation) classification system [12].

In the PEDIS classification peripheral arterial occlusive disease (PAOD) is grade 2 if presence of symptoms or signs of PAOD but not of critical limb ischemia (CLI): presence of intermittent claudication or Ankle Brachial Index $(\mathrm{ABI})<0.9$ (but with systolic ankle pressure $>50 \mathrm{mmHg}$ ) or Toe brachial Index $<0.6$ (but with systolic toe blood pressure $>30 \mathrm{mmHg}$ ) or Transcutaneous Pression of $\mathbf{O 2}$ (TcPO2) is $30-60 \mathrm{mmHg}$ or other abnormalities on noninvasive testing, compatible with peripheral arterial disease but not with critical limb ischemia. Peripheral arterial disease is grade 3 (critical limb ischemia) if systolic ankle blood pressure is $<50 \mathrm{mmHg}$ or systolic toe blood pressure is $<30 \mathrm{mmHg}$ or TcPo $2<30$ $\mathrm{mmHg}$.

The PEDIS classification for sensation is as follow: grade $1=$ a normal sensation, grade 2 $=\mathbf{a}$ loss of sensitivity to the monofilament, and grade $3=$ presence of a chronic Charcot foot.

\section{Objective and outcome}

The objective of our study was to determine mortality rate at 5 years. The secondary objective was to identify the independent predictors of five-year mortality in patients with diabetic foot ulcer. 


\section{Statistical analysis}

Continuous variables are reported as mean \pm standard deviation (sd) or median [Q1; Q3] and are compared using Wilcoxon rank sum test. Categorical variables are reported as number and percentage (percentages were calculated excluding missing data) and are compared by Chi-2 lcertest or Fisher's exact test, as appropriate. Missing data had not been imputed.

Time to death after inclusion was analyzed using Kaplan Meier method. Estimate rate at 1, 3 and 5 years and their $95 \%$ confidence interval (CI) are presented. Patients who were known to be alive at five-year or lost-to follow up were censored at five years or at the last contact date. For some patients, information on death was known, but the date of death could not be recovered. In order to take these patients into consideration, 2 analyses were performed: these patients were considered as deceased at the latest available date of follow-up plus 1 day (primary analysis) and censored at the latest available date of follow-up (sensitivity analysis).

Risk factors of death were looked for among patients' and disease' characteristics (age, sex, ulcer duration, body mass index (BMI), lifestyle, type 2 diabetes, insulin treatment, diabetes duration, hemodialysis, active smoking, PEDIS perfusion, PEDIS sensation, University of Texas Diabetic Wound Classification System, acute hospitalization and ulcerduration during the first year of follow up (as time-dependent covariate) using Cox proportional Hazard model. Univariate analysis $(\mathbf{p}<\mathbf{0 . 1 5})$ were first performed to select potential explanatory variables that were subsequently tested in multivariate model (stepwise method). The results were interpreted in terms of adjusted hazard ratios (aHR) with their associated $95 \%$ CI.

A p-value $<0.05$ was considered significant. All statistical analyses involved the use of SAS release 9.4 (SAS Institute Inc, Cary, NC) statistical software package.

\section{Results}

Three hundred and forty-seven (347) patients were included. Five years after inclusion 49 (14\%) patients were lost to follow up (Figure 1).

The main characteristics of the patients at inclusion are given in Table 1 . Sixty eight $\%$ were male and mean age was $65+/-12$ years. Most patients were retired (62\%) and did not live alone (77\%). Eighty nine \% had type 2 diabetes, $71 \%$ were treated with insulin and duration of diabetes was $16[10 ; 27]$ years. Fourteen \% of patients were active smokers, $13 \%$ were on dialysis and $7 \%$ had a organ transplant (4\% a kidney and 3\% a kidney-pancreas transplant). Seventy $\%$ of patients had peripheral arterial disease (PAOD) and $17 \%$ had grade 3 PAOD according to PEDIS classification (e.g. supplemental Table S1). Nine \% of patients had grade 
3 neuropathy (chronic Charcot foot) according to PEDIS sensation classification. $50 \%$ of patients were admitted to hospital at baseline for wound management.

Median wound duration at inclusion was 49 [19; 120] days. The distribution of ulcer gradation according to PEDIS classification and University of Texas Diabetic Wound Classification System is given in supplemental Tables S1 and S2.

Compared with patients not lost to follow-up $(\mathbf{N}=\mathbf{2 9 8})$, patients lost to follow up $(\mathbf{N}=\mathbf{4 9})$ had a longer ulcer duration at inclusion $(66[30 ; 155]$ versus $46[18 ; 114]$ days; $p=0.04)$, a more frequent grade 4 infection ( $6 \%$ versus $0.3 \% ; \mathrm{p}=0.018)$ and they required more frequently to be admitted (68 versus 48\%; $\mathrm{p}=0.02$ ). But they were not different for age, diabetes duration, severe comorbidity like dialysis or organ graft, and pedis perfusion classification.

According to Kaplan Meier method, the non-healing rate at one year of follow up was $32.8 \%[27.4 ; 38.3]$.

\section{Mortality rate}

The five-year mortality rate was 35\% [30; 41] (primary analysis). Mortality rate was 10\% at year 1 and $25 \%$ at year 3. (Figure 2a).

\section{Independent predictors of five-year mortality}

Mortality at year 5 was associated with age, diabetes duration, dialysis, PEDIS perfusion grade, PEDIS sensation grade, wound University of Texas classification stages $\mathbf{C , D}$ and ulcer duration during the first year of follow up (Table 2).

Independent predictors of five-years mortality were higher age, higher diabetes duration, PEDIS perfusion grade 2 or 3 , and ulcer duration during the first year of follow up (Table 3). These results were consistent in the sensitivity analyze (data not shown).

Mortality rate according to PEDIS perfusion grade is shown in supplemental table S3 and survival curves in Figure 2b. Patients with grade 1 PEDIS perfusion (no peripheral arterial disease, neuropathic foot ulcer) had a survival rate of 100, 91 and $84 \%$ at respectively 1,3 and 5 years.

\section{Discussion}

The 5-year mortality rate of patients presenting a new diabetic foot ulcer in the years 2009-2010 was $35 \%$. The most appropriate study to make a comparison with our data is the one of Morbach and col [10] on patients presenting with DFU in 1998-1999, because patients 
seems to be nearly comparable. Despite a bit higher rate of severe comorbidities in our cohort compared with Morbach's one (respectively $13 \%$ of patients on dialysis versus $4 \%, 70 \%$ of patients with peripheral arterial disease versus 55\%) we found a lower mortality rate: $35 \%$ compared with $46 \%$. Importantly in patients without peripheral arterial disease (isolated neuropathy) the mortality rate in our cohort is much smaller $(16 \%)$ and twice as lower than in the Morbach's cohort (30\%). The difference is smaller for patients with peripheral arterial disease, but presents: $43 \%$ compared with 59\%. The mortality rate in our cohort is also lower than in others cohorts followed before the years $2010[6,13]$. These results suggest that life expectancy has improved in patients with diabetic foot ulcer.

Young and col in 2008 [5] already suggested this increase in life survival in patients with diabetic foot ulcer. They even reported a low $27 \%$ mortality rate, but patients in their cohort were younger than in our (62 years old versus 65 ) with a shorter duration of diabetes (14 years) and a less frequent peripheral arterial disease (50\%), all these factors influencing mortality.

Interestingly in a recent national observational study including patients with an active diabetic foot ulcer in the 2008-2011 years, identified from a diabetes register, the percentage of people who died during a 2 year follow up period was $16 \%$ [14], so next to the one observed in our study (see fig 2).

An improvement in life expectancy has been recently described in people with diabetes (type 1 and type 2) [8]. This is probably explained by a combination of advances [15] among which a better management of cardiovascular risk factors. The first cause of mortality in patients with diabetic foot ulcer is a cardiovascular event which explains $50 \%$ to $75 \%$ of deaths $[4,5$, 16], and we can suppose that the better management of cardiovascular risk factors also regard these patients. Another explanation could be the improvement of foot ulcer management observed in the last years, with a lower rate of major amputation when patients are referred to diabetic foot ulcer centers, like in the current cohort where the major amputation rate was $10 \%$ at year 1 (data not shown). This may improve health related quality of life and decrease depression, two components that are predictive of mortality $[17,18]$ in this population.

In our cohort, the strongest independent predictive factor of mortality at year 5 was severe peripheral arterial disease (grade 3 of the PEDIS classification), which is an expected risk factor for mortality $[5,10]$. It is assumed that the severity of peripheral arterial disease is a strong reflection of the general health and cardio-vascular patient's condition. Interestingly the wound duration during the first year was another important independent factor associated with 5-year mortality (HR: 2.09). To our knowledge, no previous studies have already tested the association with this variable. The persistence of a non-healed foot ulcer exposes to infection, but this is not a frequent cause of mortality, and PEDIS infection was not associated with mortality in our study (data not shown). It is more likely that a prolonged non healed ulcer reflects the presence of several factors that may increase the risk 
of death, like undernutrition, depression, carelessness and poor adherence to treatments. In the Eurodial study [19] a low health-related quality of life (HRQoL) especially in the physical domain, was associated with death in people with DFU after adjustment for possible confounders. Authors suggested that strategies that improve mobility, reduce pain, and enable patient to better perform daily activities might have beneficial effects on the outcome, in addition to biomedical interventions focused on wound treatment. Depression which can reduce self-care is also associated with mortality at five years in people with diabetic foot ulcer [18].

The strengths of our study are the high number of patients, the prospective design and the low rate of lost to follow up. Weaknesses of our study are the monocentric recruitment, the absence of a comparative group, and the absence of data on drug therapies and causes of death.

\section{Conclusions}

In the years 2009-2010, mortality rate at year 5 of patients presenting with a new diabetic foot ulcer is not as high as observed before the 2000s, suggesting that these patients benefit of a better health care like all people with diabetes. This result emphasizes that diabetic foot ulcer should not be considered as a terminal illness, and that clinicians need to address risk factors for mortality aggressively in these patients to improve chances of survival. Particularly in patients with neuropathic foot ulcer, the chance to be still alive after five years is high: it concerns $84 \%$ of patients. Importantly, patients with a long duration non-healed ulcer are at high risk of mortality at five year independently of peripheral arterial disease and age. These patients could probably have benefit of a better global care, taking into account nutrition, psychological health and daily well-being, but this remains to be tested in future studies.

\section{Acknowledgments}

We thank Eli Lilly Company for having supported this work.

\section{Funding}

This work was supported by Eli Lilly Company.

\section{Contribution statement}

C.A. researched data and wrote the manuscript. A.C. researched data and wrote the manuscript. C.A. contributed to the discussion. O.B. reviewed the manuscript. C.A. researched data. T.C. researched data. E.F. researched data. G.H.V. helped design the study and researched data. SR carried out all statistical analysis and reviewed the manuscript. A.H. designed the study, wrote the manuscript and contributed to the discussion. 
A.H. is the guarantor of this work and, has full access to all the data, and takes responsibility for the integrity of the data.

\section{References}

[1] Reiber GE, Lipsky BA, Gibbons GW. The burden of diabetic foot ulcers. Am J Surg 1998; 176 (2A Suppl):5S-10S. https://doi.org/10.1016/S0002-9610(98)00181-0

[2] Boulton AJ, Vileikyte L, Ragnarson-Tennvall G, Apelqvist J. The global burden of diabetic foot disease. Lancet 2005; 366: 1719-24. https://doi.org/10.1016/S0140-6736(05)67698-2

[3] Boyko EJ, Ahroni JH, Smith DG, Davignon D. Increased mortality associated with diabetic foot ulcer. Diabet Med 1996; 13:967-72.https://doi.org/10.1002/(SICI)10969136(199611)13:11<967::AIDDIA266>3.0.CO;2-K

[4] Iversen MM, Tell GS, Riise T, et al. History of Foot Ulcer Increases Mortality Among Individuals With Diabetes. Diabetes Care 2009; 32 :2193-2199. https://doi.org/10.2337/dc09-0651

[5] Young MJ, McCardle JE, Randall LE, Barclay JI. Improved survival of diabetic foot ulcer patients 1995-2008: possible impact of aggressive cardiovascular risk management. Diabetes Care 2008; 31:2143-2147. https://doi.org/10.2337/dc08-1242

[6] Moulik PK, Mtonga R, Gill GV. Amputation and mortality in new-onset diabetic foot ulcers stratified by etiology. Diabetes Care 2003; 26:491-494. https://doi.org/10.2337/diacare.26.2.491

[7] Dale AC, Vatten LJ, Nilsen TI, Midthjell K, Wiseth R. Secular decline in mortality from coronary heart disease in adults with diabetes mellitus: cohort study. BMJ 2008; 337:99-102. https://doi.org/ 10.1136/bmj.39582.447998.BE

[8] Rawshani A, Rawshani A, Franzén S et al. Mortality and Cardiovascular Disease in Type 1 and Type 2 Diabetes. N Engl J Med 2017; 376:1407-1418. https://doi.org/10.1056/NEJMoa1608664

[9] Bus SA, Armstrong DG, van Deursen RW et al. IWGDF guidance on footwear and offloading interventions to prevent and heal foot ulcers in patients with diabetes. Diabetes Metab Res Rev 2016; 32 Suppl 1:25-36. https://doi.org/10.1002/dmrr.2697

[10] Morbach S, Furchert H, Gröblinghoff U et al. Long-term prognosis of diabetic foot patients and their limbs: amputation and death over the course of a decade. Diabetes Care 2012; 35:2021-2027. https://doi.org/10.2337/dc12-0200

[11] Armstrong DG, Lavery LA, Harkless LB. Validation of a diabetic wound classification system. The contribution of depth, infection, and ischemia to risk of amputation. Diabetes Care 1998; 21(5): 855-859. https://doi.org/10.2337/diacare.21.5.855

[12] Chuan F, Tang K, Jiang P, Zhou B, He X. Reliability and validity of the perfusion, extent, depth, infection and sensation (PEDIS) classification system and score in patients with diabetic foot ulcer. PloS One 2015; 10:e124739. https://doi.org/10.1371/journal.pone.0124739

[13] Ghanassia E, Villon L, Thuan dit Dieudonné J-F, Boegner C, Avignon A, Sultan A. Long-Term Outcome and Disability of Diabetic Patients Hospitalized for Diabetic Foot Ulcers. Diabetes Care 2008; 31:1288-1292. https://doi.org/10.2337/dc07-2145 
[14] Vadiveloo, T., Jeffcoate, W., Donnan, P.T. et al. Amputation-free survival in 17,353 people at high risk for foot ulceration in diabetes: a national observational study. Diabetologia 2018; 61: 2590-2597. https://doi.org/10.1007/s00125-018-4723-y

[15] Tricco AC, Ivers NM, Grimshaw JM et al. Effectiveness of quality improvement strategies on the management of diabetes: a systematic review and meta-analysis. Lancet 2012; 379:2252-2261. https:// doi.org/10.1016/S0140-6736(12)60480-2

[16] Chammas NK, Hill RLR, Edmonds ME. Increased Mortality in Diabetic Foot Ulcer Patients: the Significance of Ulcer Type. J Diabetes Res 2010; 2016:2879809. http://dx.doi.org/ $\underline{10.1155 / 2016 / 2879809}$

[17] Williams LH, Rutter CM, Katon WJ et al. Depression and incident diabetic foot ulcers: a prospective cohort study. Am J Med 2010; 123:748-754. https://doi.org/10.1016/j.amjmed. 2010.01 .023

[18] Winkley K, Sallis H, Kariyawasam D et al. Five-year follow-up of a cohort of people with their first diabetic foot ulcer: the persistent effect of depression on mortality. Diabetologia 2012; 55:303-310. https://doi.org/10.1007/s00125-011-2359-2

[19] Siersma V, Thorsen H, Holstein PE et al. Health-related quality of life predicts major amputation and death, but not healing, in people with diabetes presenting with foot ulcers: the Eurodiale study. Diabetes Care 2014; 37:694-700. https://doi.org/10.2337/dc13-1212

\section{Figure Legends:}

Figure 1: Study Flow Chart

Figure 2 : Kaplan Meier curve of survival, overall (a) and according to PEDIS Perfusion (b). Estimate rate $[95 \% \mathrm{Cl}]$ 
Figure 1

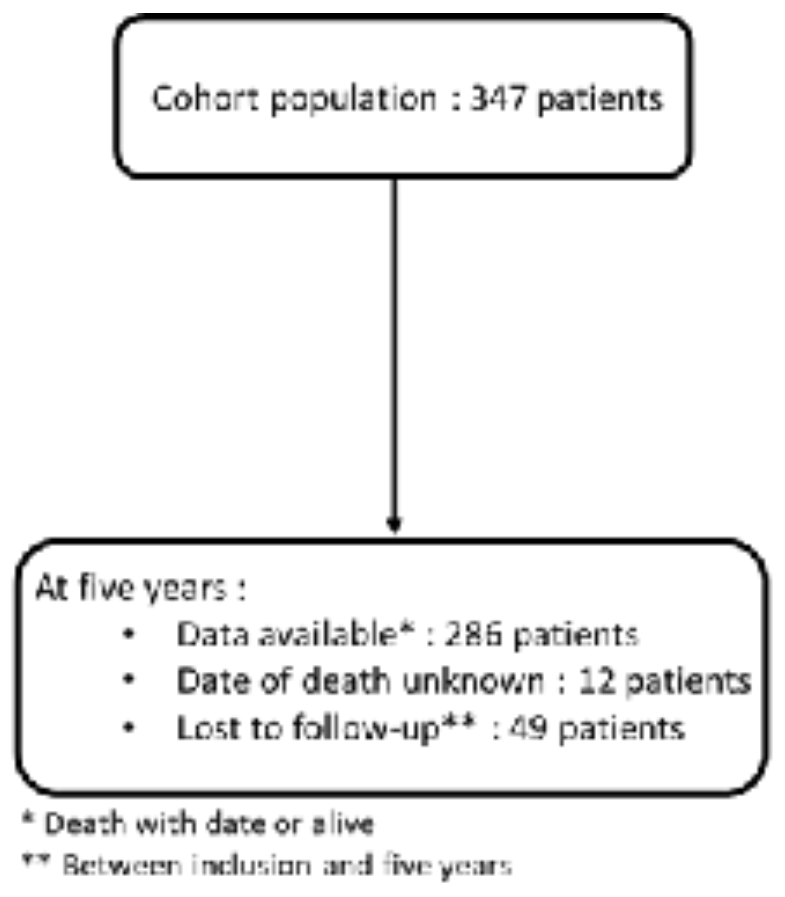


Figure 2

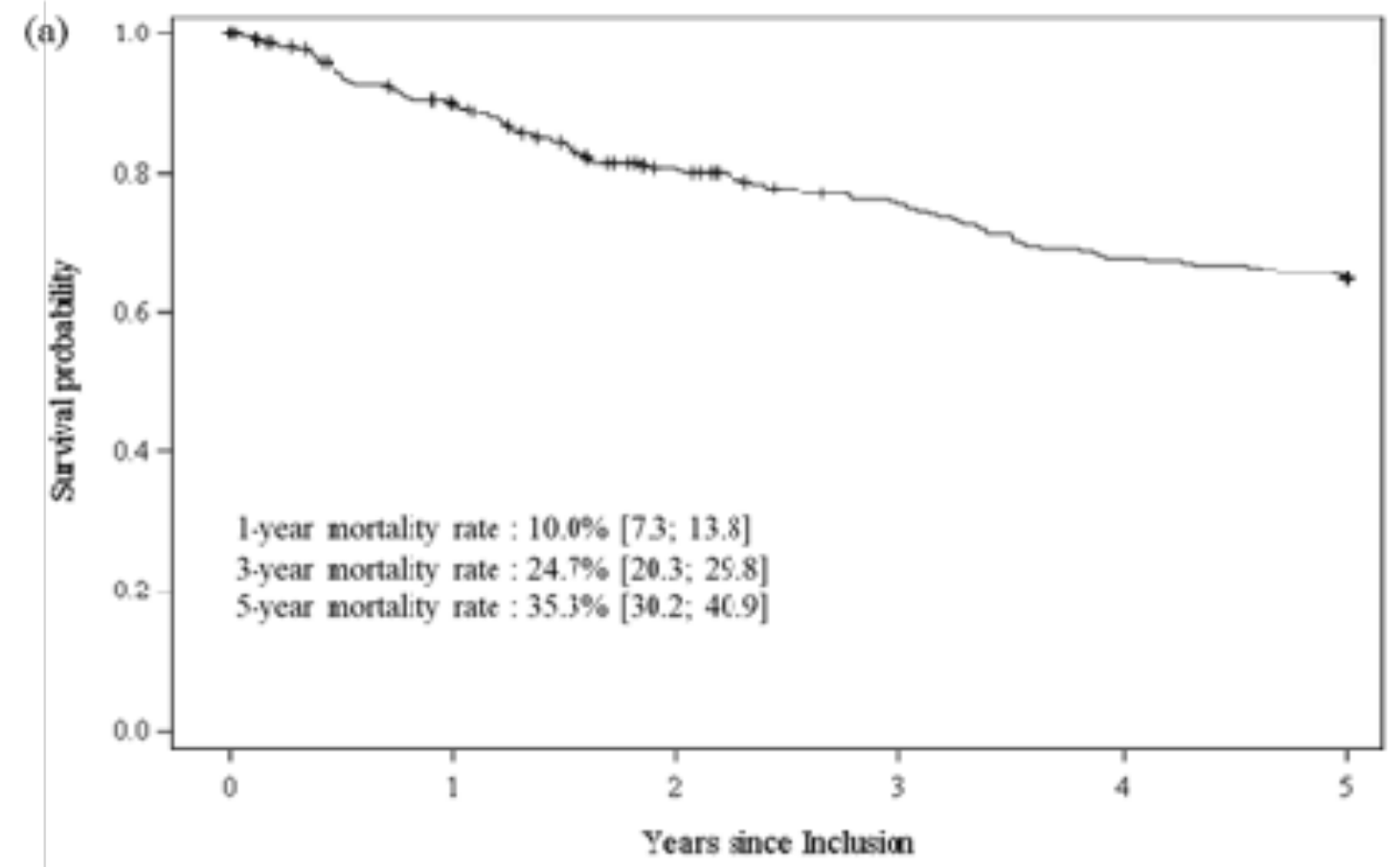

$\begin{array}{llllll}\text { No at risk } & 367 & 280 & 264 & 200 & 10 \pm\end{array}$

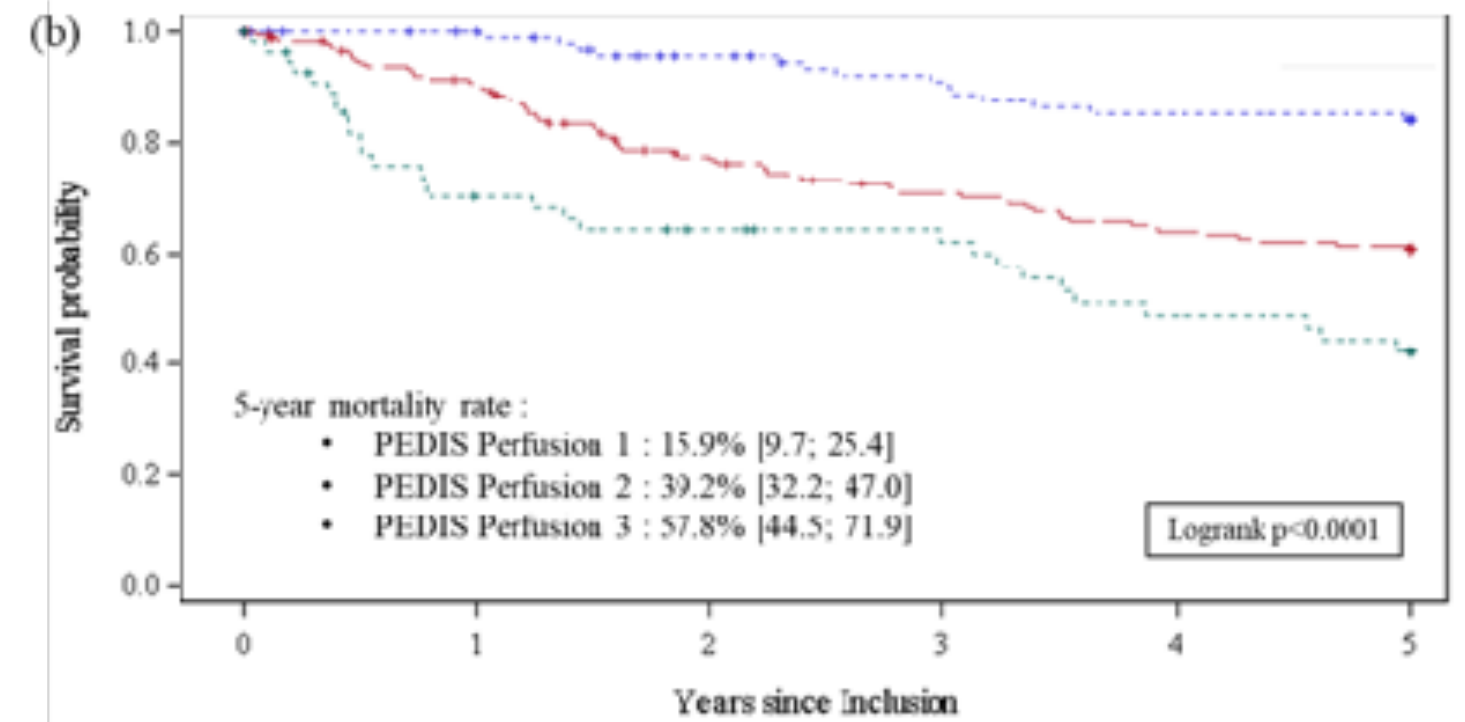

since Inchusia

\begin{tabular}{|c|c|c|c|c|c|}
\hline \multicolumn{6}{|c|}{ PEDIS Perfusion } \\
\hline 105 & 95 & 35 & 78 & 7) & 72 \\
\hline 134 & 158 & 128 & 114 & 103 & 98 \\
\hline 58 & 36 & 31 & 28 & 2 & 19 \\
\hline
\end{tabular}


Table 1. Baseline characteristics of patients $(n=347$

\begin{tabular}{|c|c|c|}
\hline & & $\begin{array}{c}\text { number of missing } \\
\text { observations }\end{array}$ \\
\hline Age (year) & $65+/-12$ & 0 \\
\hline Men (\%) & $237(68.3)$ & 0 \\
\hline $\mathrm{BMI}(\mathrm{kg} / \mathrm{m} 2)$ & $28.5+/-6.0$ & 22 \\
\hline Active smoking (\%) & $48(14.4)$ & 13 \\
\hline Do not live alone (\%) & $256(76.9)$ & 14 \\
\hline Dialysis (\%) & $44(12.7)$ & 0 \\
\hline Type 2 diabetes (\%) & $308(89.0)$ & 1 \\
\hline Duration of diabetes (years) & $19+/-12$ & 4 \\
\hline Insulin treatment (\%) & $245(71.4)$ & 4 \\
\hline Duration of foot ulcer (days) & $49[19 ; 120]$ & 3 \\
\hline $\begin{array}{l}\text { Acute hospitalization at baseline } \\
\text { (\%) }\end{array}$ & $154(50.2)$ & 40 \\
\hline $\begin{array}{l}\text { PEDIS Perfusion (\%) } \\
1 \\
2 \\
3\end{array}$ & $\begin{array}{c}105(30.3) \\
184(53.0) \\
58(16.7)\end{array}$ & 0 \\
\hline $\begin{array}{c}\text { PEDIS Sensation (\%) } \\
1 \\
2 \\
3\end{array}$ & $\begin{array}{c}58(16.7) \\
259(74.6) \\
30(8.6)\end{array}$ & 0 \\
\hline $\begin{array}{l}\text { TEXAS Classification (\%) } \\
\text { A } \\
\text { B } \\
\text { C } \\
\text { D }\end{array}$ & $\begin{array}{c}87(25.1) \\
50(14.4) \\
97(28.0) \\
113(32.6)\end{array}$ & 0 \\
\hline
\end{tabular}

Data are expressed as mean +/- SD, median [Q1; Q3] or N (\%)

* Kaplan-Meier estimate [95\% Cl] 
Table 2: Predictors of five-year mortality

\begin{tabular}{|c|c|c|}
\hline Factors & $\begin{array}{l}\text { Univariate analysis } \\
\text { HR [95\% CI] } \\
\text { p-value }\end{array}$ & $\begin{array}{l}\text { Multivariate analysis* } \\
\text { aHR }[95 \% \mathrm{Cl}] \\
\text { value }\end{array}$ \\
\hline $\begin{array}{l}\text { Age } \\
\text { (per additional year) }\end{array}$ & $\begin{array}{l}1.06[1.04 ; 1.08] \\
<0.001\end{array}$ & $\begin{array}{l}1.05[1.03 ; 1.07] \\
<0.001\end{array}$ \\
\hline Sex (female vs. male) & $\begin{array}{l}1.16[0.78 ; 1.72] \\
0.469\end{array}$ & \\
\hline $\begin{array}{l}\text { Ulcer duration at baseline } \\
\text { (per additional day) }\end{array}$ & $\begin{array}{l}0.999[0.998 ; 1.00] \\
0.037\end{array}$ & \\
\hline $\begin{array}{l}\mathrm{BMI}\left(\mathrm{kg} / \mathrm{m}^{2}\right) \\
\text { (per additional unit) }\end{array}$ & $\begin{array}{l}0.97[0.93 ; 1.00] \\
0.071\end{array}$ & \\
\hline $\begin{array}{l}\text { Do not live alone } \\
\text { (vs. live alone) }\end{array}$ & $\begin{array}{l}1.17[0.73 ; 1.87] \\
0.515\end{array}$ & \\
\hline Type 2 diabetes & $\begin{array}{l}1.24[0.67 ; 2.32] \\
0.496\end{array}$ & \\
\hline Insulin treatment & $\begin{array}{l}1.29[0.84 ; 1.995] \\
0.251\end{array}$ & \\
\hline $\begin{array}{l}\text { Duration of diabetes } \\
\text { (per additional year) }\end{array}$ & $\begin{array}{l}1.02[1.003 ; 1.03] \\
0.021\end{array}$ & $\begin{array}{l}1.02[1.001 ; 1.03] \\
0.032\end{array}$ \\
\hline Hemodialysis & $\begin{array}{l}1.75[1.05 ; 2.90] \\
0.031\end{array}$ & \\
\hline Active smoker & $\begin{array}{l}0.79[0.43 ; 1.44] \\
0.433\end{array}$ & \\
\hline $\begin{array}{l}\text { PEDIS Perfusion } \\
1 \\
2 \\
3\end{array}$ & $\begin{array}{l}<0.001 \\
1.00 \\
3.02[1.70 ; 5.38] \\
<0.001 \\
5.47[2.89 ; 10.35] \\
<0.001\end{array}$ & $\begin{array}{l}0.004 \\
1.00 \\
2.35[1.28 ; 4.29] \\
0.006 \\
3.14[1.58 ; 6.24] \\
0.001\end{array}$ \\
\hline $\begin{array}{l}\text { PEDIS Sensation } \\
\quad 1 \\
2 \\
3\end{array}$ & $\begin{array}{l}0.030 \\
1.00 \\
1.30[0.78 ; 2.19] \\
0.319 \\
0.30[0.09 ; 1.01] \\
0.525\end{array}$ & \\
\hline $\begin{array}{l}\text { TEXAS Classification } \\
\text { A } \\
\text { B } \\
\text { C } \\
\text { D }\end{array}$ & $\begin{array}{l}<0.001 \\
1.00 \\
0.81[0.33 ; 2.01] \\
0.649 \\
3.20[1.75 ; 5.85] \\
<0.001 \\
2.75[1.51 ; 5.01] \\
0.001\end{array}$ & \\
\hline
\end{tabular}


Acute hospitalization at baseline

$1.03[0.69 ; 1.55]$

0.878

Ulcer duration during the first

year

of follow up**

$2.04[1.37 ; 3.0$.

$<0.001$

$2.09[1.35 ; 3.22]$

$<0.001$

* $\mathrm{N}=319$

** time-dependent covariate

aHR : adjusted Hazard Ratio 